\title{
The Levels of Serum C - reactive protein and Creatine Kinase-MM in Human Immunodeficiency Virus Seropositive Subjects Co-infected with Plasmodium falciparum
}

\author{
Digban Kester ${ }^{1}$, Ehiaghe Friday Alfred ${ }^{1,2, *}$ \\ ${ }^{1}$ Department of Medical Laboratory Science, College of Health Sciences, Igbinedion University, Okada, Nigeria \\ ${ }^{2}$ Department of Hematology and Immunohematology, College of Health Sciences, Igbinedion University, Okada, Nigeria
}

Email address:

fredleo2547@yahoo.com (E. F. Alfred)

*Corresponding author

\section{To cite this article:}

Digban Kester, Ehiaghe Friday Alfred. The Levels of Serum C - Reactive Protein and Creatine Kinase-MM in Human Immunodeficiency Virus Seropositive Subjects Co-infected with Plasmodium falciparum. International Journal of Immunology.

Vol. 5, No. 2, 2017, pp. 37-40. doi: 10.11648/j.iji.20170502.12

Received: March 4, 2017; Accepted: March 24, 2017; Published: April 14, 2017

\begin{abstract}
The present study was designed to determine the levels of C-reactive protein and creatine kinase-MM in Nigerian naïve (stage 2) HIV seropositive subjects co-infected with Plasmodium falciparum. A total of 204 subjects (aged between 18 and 45 years) were randomly studied. Among these were 74 naïve (stage 2) HIV seropositive subjects (confirmed by Western blot method), 70 naïve (stage 2) HIV seropositive subjects co-infected with P. falciparum (confirmed by Western blot and microscopic methods respectively) and 60 apparently healthy individuals (confirmed to be negative for Human immunodeficiency virus and P. falciparum by Western blot and microscopic methods respectively). Absolute lymphocyte counts was estimated using Sysmex ${ }^{\circledR}$ Automated Hematology Analyzer, whereas $\mathrm{CD} 4^{+}$cell count was estimated using Partec $\AA$ Cyflow Counter. C-reactive protein and creatine kinase was estimated using enzyme-linked immunosorbent assay methods. The creatine kinase-MM and C-reactive protein concentrations were significantly higher in HIV seropositive subjects coinfected with malaria when compared with the controls subjects $(\mathrm{P}=0.000)$ respectively. Whereas the absolute lymphocyte counts and $\mathrm{CD}^{+} \mathrm{T}$ cell counts were significantly lower in HIV seropositive subjects co-infected with malaria when compared with the controls subjects $(\mathrm{P}=0.000)$. The increased expression of $\mathrm{C}$ - reactive protein and creatine kinase-MM coupled with the decrease in absolute lymphocyte and $\mathrm{CD}^{+}$cell counts significantly contributes to the pathogenesis of HIV and $P$. falciparum infections.
\end{abstract}

Keywords: C - reactive Protein, Creatine Kinase-MM, Human Immunodeficiency Virus, Stage 2, Plasmodium falciparum

\section{Introduction}

The levels of C-reactive proteins and creatine kinase-MM are usually elevated in response to the proinflammatory cytokines (interleukin-1 and 6), whose expression are induced by microbial infection and skeletal muscle damage which are associated with human immunodeficiency virusand Plasmodium falciparum infections [1],[2]. It has also been reported that an elevated CRP and CK-MM are indicative of an increased risk for cardiovascular disease and colon cancer [3], [4], [5], [6], [7], [8]. Sklar et al [9] failed to find any predictive value of CRP for cardiovascular disease in HIVinfected individuals.
There is evidence of skeletal muscle damage with increased CK-MM concentration in P. falciparum infected African children [2]. Furthermore, the relationship between CRP and CK-MM concentrations in naïve HIV seropositive subjects coinfected with P. falciparum is still unclear. Based on the above reason, the study was designed to determine the levels of CRP and CK-MM in Nigerian naïve HIV seropositive subjects coinfected with $P$. falciparum. This will add to the existing level of information on Human immunodeficiency virus and $P$. falciparum infections which is beneficial. 


\section{Materials and Methods}

\subsection{Participants}

This cross sectional study was conducted at Igbinedion University Teaching Hospital in Okada Community in Ovia North East local Government Area, Edo State, Nigeria. Ethical approval was obtained from IUTH Ethical Review Committee. Informed consent was obtained from all subjects before the commencement of the study. A total of 204 subjects (aged between 18 and 45 years) were randomly studied. Among these were 74 naïve (stage 2) HIV seropositive subjects (confirmed by Western blot method), 70 naïve (stage 2) HIV seropositive subjects co-infected with $P$. falciparum (confirmed by Western blot and microscopic methods respectively) and 60 apparently healthy individuals (confirmed to be negative for human immunodeficiency virus and P. falciparum by Western blot and microscopic methods respectively).

\subsection{Blood Samples Analysis}

Eight milliliters volume of venous blood sample were collected from the ante-cubital vein of the subjects using standard laboratory collection technique and shared equally into ethylene diamine tetra acetic acid (EDTA) vacutainers and an anticoagulant free vacutainers, subsequently centrifuged at $750 \mathrm{x} \mathrm{g}$ for 15 minutes to obtain serum. The blood samples collected in EDTA were used for absolute lymphocyte counts using Sysmex ${ }^{\circledR}$ Automated Hematology Analyzer as previously described by Ehiaghe et al [10] whereas $\mathrm{CD}^{+}$cell count was estimated using Partec $\AA$ Cyflow Counter (Germany) as described by PCC [11]. The blood samples collected in the anticoagulant free vacutainers were used for C-reactive protein estimation using enzymelinked immunosorbent assay method as described by Ehiaghe et al [12]. Serum creatine kinase was estimated using enzyme-linked immunosorbent assay method as described by Ehiaghe et al [13].

\subsection{Data Analysis}

Student's t- test was used to compare independent variables. The probability values less than 0.05 were considered significant. The statistical analysis were done using SPSS version 20.0.

Table 1. Mean $\pm S D$ values of creatine kinase $(\mathrm{ng} / \mathrm{ml})$, C-reactive protein $(\mathrm{ng} / \mathrm{ml})$, absolute lymphocyte count (cells/ $\mu \mathrm{l})$ and $\mathrm{CD} 4^{+} \mathrm{T}$ cell counts $(\mathrm{cells} / \mu \mathrm{l})$ of theHIV seropositive subjects with control subjects.

\begin{tabular}{|c|c|c|c|c|}
\hline Parameters & Creatine kinase & C-reactive protein & Absolute lymphocyte count & $\mathrm{CD4}^{+} \mathrm{T}$ cell counts \\
\hline \multicolumn{5}{|l|}{ Subjects } \\
\hline $\mathrm{HIV}(\mathrm{N}=74)$ & $75 \pm 0.5$ & $8.3 \pm 1.3$ & $0.5 \pm 0.01$ & $300 \pm 5.0$ \\
\hline Controls $(\mathrm{N}=60)$ & $0.5 \pm 0.1$ & $1.2 \pm 1.20$ & $1.5 \pm 0.03$ & $800 \pm 10$ \\
\hline$P$ values & $<0.001^{*}$ & $<0.001 *$ & $<0.001 *$ & $<0.001 *$ \\
\hline
\end{tabular}

Keys

* = significant

$\mathrm{N}=$ Number of subjects

HIV $=$ HIV seropositive subjects

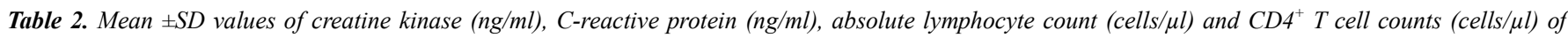
theHIV seropositive subjects co-infected with P. falciparum and the control subjects.

\begin{tabular}{lllc}
\hline Parameters & Creatine kinase & C-reactive protein & Absolute lymphocyte count \\
\hline Subjects & & & \\
\hline HIV+ MP $(\mathrm{N}=70)$ & $90.0 \pm 0.6$ & $10.3 \pm 1.0$ & $0.3 \pm 0.03$ \\
Controls $(\mathrm{N}=60)$ & $0.5 \pm 0.1$ & $1.2 \pm 0.20$ & $1.5 \pm 0.03$ \\
P values & $<0.001^{*}$ & $<0.001^{*}$ & $<0.001^{*}$ \\
\hline
\end{tabular}

Keys

* = significant

$\mathrm{N}=$ Number of subjects

$\mathrm{HIV}+\mathrm{MP}=\mathrm{HIV}$ seropositive subjects co-infected with P. falciparum

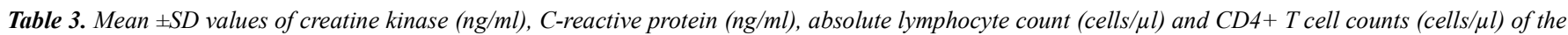
HIV seropositive subjects and HIV seropositive subjects co-infected with P. falciparum.

\begin{tabular}{llll}
\hline Parameters & Creatine kinase & C-reactive protein & Absolute lymphocyte count \\
\hline Subjects & & & \\
\hline HIV $(\mathrm{N}=74)$ & $75 \pm 0.5$ & $8.3 \pm 1.3$ & $0.5 \pm 0.01$ \\
HIV + HIV+ MP(N $=70)$ & $90 \pm 0.6$ & $10.3 \pm 1.0$ & $0.3 \pm 0.03$ \\
P values & $<0.001^{*}$ & $<0.001^{*}$ & $<0.001^{*}$ \\
\hline
\end{tabular}

Keys

* = significant

$\mathrm{N}=$ Number of subjects

$\mathrm{HIV}=\mathrm{HIV}$ seropositive subjects

HIV + MP $=$ HIV seropositive subjects co-infected with $P$. falciparum 


\section{Results}

Table 1 shows mean $\pm(\mathrm{SD})$ values of creatine kinase, $\mathrm{C}$ reactive protein, absolute lymphocyte counts and $\mathrm{CD} 4^{+} \mathrm{T}$ cell counts of the naïve HIV seropositive subjects and controls subjects. The creatine kinase and C-reactive protein concentrations were significantly higher in naïve HIV seropositive subjects when compared with the controls subjects $(\mathrm{P}<0.001)$ respectively. Whereas the absolute lymphocyte counts and $\mathrm{CD}^{+} \mathrm{T}$ cell counts were significantly lower in naïve HIV seropositive subjects when compared with the controls subjects $(\mathrm{P}<0.001)$ respectively.

Table 2 shows mean $\pm(\mathrm{SD})$ values of creatine kinase, $\mathrm{C}$ reactive protein, absolute lymphocyte counts and $\mathrm{CD} 4^{+} \mathrm{T}$ cell counts of the naïve HIV seropositive subjects co-infected with malaria and controls subjects. The creatine kinase and C-reactive protein concentrations were significantly higher in naïve HIV seropositive subjects co-infected with malaria when compared with the controls subjects $(\mathrm{P}<0.001)$ respectively. Whereas the absolute lymphocyte counts and $\mathrm{CD}^{+} \mathrm{T}$ cell counts were significantly lower in naïve HIV seropositive subjects co-infected with malaria when compared with the controls subjects $(\mathrm{P}<0.001)$ respectively.

Table 3 shows mean \pm (SD) values of creatine kinase, $C$ reactive protein, absolute lymphocyte counts and $\mathrm{CD}^{+} \mathrm{T}$ cell counts of the naïve HIV seropositive subjects and naïve HIV seropositive subjects co-infected with malaria. The creatine kinase and C-reactive protein concentrations were significantly higher in HIV seropositive subjects co-infected with malaria when compared with the HIV seropositive subjects $(\mathrm{P}<0.001)$ respectively. Whereas the absolute lymphocyte counts and $\mathrm{CD}^{+} \mathrm{T}$ cell counts were significantly lower in naïve HIV seropositive subjects co-infected with malaria when compared with the naïve HIV seropositive subjects $(\mathrm{P}<0.001)$ respectively.

\section{Discussion}

The present cross-sectional study provides evidence that the liver and skeletal muscles are involved in a variety of complications associated with naïve HIV seropositive subjects with or without $P$. falciparum co-infections in adults. However, naïve HIV seropositive subjects with or without $P$. falciparum co-infections had significantly higher CRP and CK-MM when compared with controls. Furthermore, the CRP and CK-MM was significantly higher in the naïve HIV seropositive subjects with $P$. falciparum co-infections when compared with the naïve HIV seropositive subjects without $P$. falciparum co-infections. Thus, indicating that $P$. falciparum enhances the metabolic disturbances associated with HIV infection. Timothy et al [14] and Bryan et al [15] reported that liver and skeletal muscles are important site for HIV and $P$. falciparum sequestration, which could contributes to the metabolic disturbances and renal complications associated with HIV and $P$. falciparum infections. Renal failure and cardiovascular disease are common and life-threatening complication in HIV and P. falciparum infections [11], [16]. It is possible that the microbial sequestration might damage muscle cells without inducing overt rhabdomyolysis (Serum CK-MM concentration $>1000 \mathrm{U} / \mathrm{L}$ ) which is absent in these study.

The naïve HIV seropositive subjects with or without $P$. falciparum co-infections had significantly lower absolute lymphocyte count and $\mathrm{CD}^{+}$lymphocyte count when compared with controls. Furthermore, the absolute lymphocyte count and $\mathrm{CD}^{+}$lymphocyte count was significantly lower in the naïve HIV seropositive subjects with $P$. falciparum co-infections when compared with the HIV seropositive subjects without $P$. falciparum coinfections. These results indicate that elevated CRP and CKMM had a reciprocal relationship with absolute lymphocyte count and $\mathrm{CD}^{+}$lymphocyte count in naïve HIV seropositive subjects with or without $P$. falciparum co-infections. It has been reported that HIV-infected patients correlate with a gradual reduction in absolute lymphocyte count and CD4 ${ }^{+}$lymphocyte count [17], [18], enumeration of $\mathrm{CD}^{+}$ lymphocyte count, therefore aid in the diagnosis of HIV/AID, well as in the assessment of response to highly active antiretroviral therapy (HAART) [19], [20].Although, these results suggest that $\mathrm{CRP}$ and $\mathrm{CK}-\mathrm{MM}$ concentration may have prognostic values, such measurement should be used in combination with $\mathrm{CD}^{+}$lymphocyte count and HIV RNA levels for monitoring HIV-infected subjects on HAART.

\section{Conclusion}

The increased expression of $\mathrm{C}$ - reactive protein and creatine kinase-MM coupled with the decrease in absolute lymphocyte and $\mathrm{CD} 4^{+} \mathrm{T}$ cell counts significantly contributes to the pathogenesis of Human immunodeficiency virus and $P$. falciparum infections. The molecular mechanism needs further investigation.

\section{References}

[1] Gabay C and Kushner I. Acute-phase proteins and other systemic responses to inflammation. N Engl J Med. 1999; 340: 448-454.

[2] Miller KD, White NJ, Lott JA, Roberts JM, Greenwood BM. Biochemical evidence of muscle injury in African children with severe malaria. J Infect Dis. 1989; 159: 139-142.

[3] Erlinger TP, Platz EA, Rifai N, Helzlsouer KJ. C-reactive protein and the risk incident colorectal cancer. JAMA. 2004; 291:585-590.

[4] Ridker PM. Clinical application of C-reactive protein for cardiovascular disease detection and prevention. Circulation. 2003; 107: 363-369.

[5] Grutzmeier S and Sandstrom E. C-reactive protein levels in HIV complicated by opportunistic infections and infections with common bacterial pathogens. Scand J Infect Dis. 1999; 31: 229-234. 
[6] Jahoor F, Gazzard B, Phillips G. The acute-phase protein response to human immunodeficiency virus infection in human subjects. Am J Physiol. 1999; 276: 1092-1098.

[7] Jupe D. The acute phase response and laboratory testing. AustFam Physician. 1996; 25:324-329.

[8] Henry K, Kitch D, Dube M. Adult AIDS Clinical Trial Group. C-reactive protein levels over time and cardiovascular risk in HIV-infected individuals suppressed on an indinavir-based regimen: AIDS Clinical Trials Group 5056s. AIDS.2004; 18: 2434-2437.

[9] Sklar PA, Nayak GS, Blackwelder WC. Predictive value of Creactive protein versus traditional risk factors for cardiovascular events among HIV infected patients. Paper presented at $44^{\text {th }}$ Annual Meeting of the Interscience Conference on Antimicrobial Agents and Chemotherapy, October 30-November 2, 2004; Washington, DC, Abstract H159.

[10] Ehiaghe FA, Onyenekwe CC, Akosile CO, Okoye C, Maruf FA, Agbonlahor DE, Uwabor CI, Ehiaghe IJ, Ogbu EC. The expression pattern and role of interferon gamma genes in exhaustive exercise. J Advan Bio. 2016. 9: 1903-1910.

[11] PCC. Typical steps of particle analysis using Partec Cyflow Counter. Instrument operating manual, partec $\mathrm{GmbH}$ OttoHann-str 32, D-48161 Munster, Germany, Pp 5-8.

[12] Ehiaghe FA. Some physiochemical changes associated with type 2 diabetes mellitus in Benin City, Nigeria. Inter J Bio and ChemSci. 2015, 9: 2582-2588.

[13] Ehiaghe F A, Onyenekwe C C, Akosile C O, Ehiaghe IJ,
Oyeyemi A W, Ifeanyichukwu M O. Some lymphocytic gene expression patterns associated with acute exercise in young male undergraduates. Am J Biotec and Mol Sci. 2016, 5: 8-22.

[14] Timothy M E D, Emsri P W S, Sasithorn P T H, Paul H, Nicholas J W. Skeletal muscle involvement in falciparum malaria: Biochemical and ultra-structural study. Infec Dis Soc Am. 1999. 29: 831-835.

[15] Bryan L, Richey A S, Larry A K, Wendy P, Frank J P, Barbara V, Stephen J G. C-reactive protein is a marker for human immunodeficiency virus disease progression. Arch Intern Med. 2006. 166: 64-70.

[16] White NJ and Ho M. The pathophysiology of malaria. Adv Parasitol. 1992. 31: 83-173.

[17] Lederman M M, Connick E, Landay A, Kuritzkes D R, Spritzler J, Clair M. Immunologic responses associated with 12 weeks of combination antiretroviral therapy: Results of AIDS Clinical Trials Group Protocol 315. J Infec Dis. 1998. 178: 70-79.

[18] Lederman M M. Immune restoration and CD4+ $\mathrm{T}$ cell function with antiretroviral therapies. AIDS.2001. 15: 11-15.

[19] Akanmu R A, Akinsete I, Eshojonie A O, Davies A O. Absolute lymphocytes count as surrogate for CD4 cell count in monitoring response to antiretroviral therapy. Nig Post Med J AIDS. 2001. 8: 105-111.

[20] Palella F J, Delori-Knoll M, Chmiel J S. Survival benefit of initiating antiretroviral therapy in HIV-infected persons in different $\mathrm{CD}^{+}$cell strata. Ann Intern Med. 2003. 138: 620626. 